\title{
Calibração de um Modelo de Rede de Distribuição de Água para um Setor de Abastecimento Real Contemplando Vazamentos
}

Fernando das Graças Braga da Silva, Luisa Fernanda Ribeiro Reis, Rodrigo de Oliveira Caliman, Fazal Hussain Chaudhry

USP - Escola de Engenharia de São Carlos - Departamento de Hidráulica e Saneamento

Av. Trabalhador Sãocarlense, 400 - 13560-250 São Carlos, S.P

fernandos2001@bol.com.br,fernanda@sc.usp.br,rocal@sc.usp.br,fazal@sc.usp.br

Recebido: 20/11/02 - revisado:: 13/05/03 - aceito: 26/06/03

\section{RESUMO}

As mudanças físicas ocorridas ao longo do tempo requerem que os modelos hidráulicos de previsão de comportamento das redes de distribuição de água para abastecimento tenham seus parâmetros reavaliados via calibração. Diversas são as dificuldades inerentes ao processo de calibração de modelos de redes reais, dentre as quais podem-se destacar aquelas resultantes da precariedade dos cadastros existentes, como a incerteza quanto à existência e posição de válvulas na rede. Muitos métodos de calibração foram propostos na literatura, geralmente com base em equações analíticas e técnicas de otimização diversas. Reconhece-se, entretanto, a necessidade de estimativas dos parâmetros da rede em termos das rugosidades e dos parâmetros locais da relação entre pressão e vazamento para sistemas sujeitos a vazamentos expressivos. Propõe-se aqui um método iterativo de calibração em duas etapas em que os AGs (algoritmos genéticos) são empregados como ferramenta na resolução dos problemas inversos correspondentes, cujos resultados demonstram-se robustos em identificar rugosidades e trechos dotados de válvulas, bem como os parâmetros do modelo de vazamentos.

Palavras-Chave: redes de distribuição de água, algoritmos genéticos, calibração.

\section{INTRODUÇÃO}

Vários pesquisadores têm discutido a calibração de modelos de redes de distribuição de água, desenvolvendo métodos de resolução geralmente baseados em equações analíticas ou técnicas de otimização utilizadas para a resolução do problema inverso correspondente. Técnicas baseadas em modelos analíticos apresentam aplicabilidade restrita a redes muito pequenas; alternativamente, requerem que uma rede grande seja simplificada, considerando apenas as tubulações principais. Assim, os mais promissores procedimentos de resolução do problema de calibração são baseados nos métodos de otimização. Entretanto, o sucesso da calibração geralmente depende de suposições linearizantes ou cálculo não realístico de derivadas parciais, através de procedimentos de otimização local, que tendem a tornar-se aprisionados em mínimos locais ou sofrer instabilidades numéricas associadas à inversão de matrizes. Portanto as técnicas clássicas de otimização requerem muitas simplificações, que por sua vez tendem a produzir resultados insatisfatórios ou pouco realísticos.

Os Algoritmos genéticos (AGs) mostram-se adequados para dar tratamento a problemas de otimização cujas funções são descontínuas e complexas e estes vem sendo utilizados para calibração de modelos de redes de distribuição de água (Savic \& Walters,1997; Walters et al. 1998).

Se por um lado, métodos de otimização não convencionais como os AGs podem representar ferramentas mais adequadas ao tratamento do problema de calibração (Silva, 2003), por outro, diversas são as dificuldades envolvidas em se tratando de uma rede real. Uma dessas dificuldades diz respeito ao fato de que os vazamentos não podem ser ignorados pelo modelo, quando estes assumem proporções consideráveis da vazão abastecida. Nesse caso em conformidade com o estudo já realizado (Caliman et. al , 2001), o modelo de calibração deve estimar os parâmetros da rede propriamente dita e do modelo de vazamentos conjuntamente.

Assim um modelo de duas fases é proposto neste trabalho e aplicado a um setor de rede real da Cidade de São Carlos, SP, utilizando a sistemática de busca dos AGs.

\section{CALIBRAÇÃO DE MODELOS DE REDES DE DISTRIBUIÇÃO DE ÁGUA}

O reconhecimento da necessidade de calibração de modelos de redes de distribuição faz com que o tema receba atenção especial na literatura, desde o trabalho clássico de Shamir \& Howard (1977), que define calibração como sendo a determinação de características físicas e operacionais de um sistema existente e obtenção de dados 
tais que, quando aplicados ao modelo matemático da rede, produzam resultados realísticos.

Posteriormente, Walski (1983) deu novo impulso aos estudos de calibração, estabelecendo alguns parâmetros práticos quanto à concordância entre o desempenho real e simulado pelos modelos. Ele estabeleceu níveis de concordância entre os valores observados e os simulados. Fez também recomendações de como proceder para calibrar modelos de redes, explicitando fórmulas para melhorar os valores de C (fator de Hazen - Wiliams).

Ormsbee \& Wood (1986) apresentaram um método de calibração baseado em modelos de simulação, considerando o fator de rugosidade das tubulações e as demandas nas junções, idealizadas constantes. Apresentaram uma aproximação bastante simples, que pode produzir bons resultados para uma extensa faixa de aplicações.

Ormsbee (1989) apresentou um procedimento que considera condições múltiplas de demanda, através de um algoritmo implícito para calibração de modelos de redes de distribuição de água. O modelo de calibração usa um método de otimização não linear ajustando os parâmetros de uma rede. Esses parâmetros incluem: rugosidade das tubulações e demandas de água. O problema de calibração de modelos de redes de distribuição de água foi expresso como a minimização das diferenças entre os valores observados e previstos para vários pontos da rede, criteriosamente escolhidos, sob diferentes condições operacionais do sistema. Tais valores podem incluir pressões, vazões ou níveis de reservatórios. $O$ procedimento se baseia em técnicas de otimização clássicas cujas dificuldades geralmente envolvem a necessidade de funções contínuas ou avaliações de derivadas.

Boulos \& Wood (1990) revêem o problema, introduzindo equações adicionais de conservação de massa e energia, estabelecendo restrições sobre as vazões em seções críticas dos condutos e as pressões requeridas em nós específicos. Um algoritmo explícito é apresentado para determinar diretamente uma variedade de parâmetros de projeto, operação e calibração para redes de distribuição de água. A resolução do problema é baseada na reformulação das equações de equilíbrio da rede em regime de escoamento permanente em termos dos parâmetros do sistema de tubulações especificado. Uma vez que estas equações são não-lineares, o método incremental de Newton Raphson é usado como procedimento básico de solução; procedimento que lineariza os termos não lineares e resolve o sistema de equações lineares simultâneas resultantes. A proposta oferece condições para se determinar explicitamente uma variedade de parâmetros de projeto, operação e de calibração para redes de distribuição de água. Observa-se que as linearizações introduzidas podem representar prejuízos em termos de resultados obtidos.

Alguns trabalhos, tais como Pudar \& Liggett (1992) e Ligget \& Chen (1994) têm visado o problema do controle de vazamentos, que requer informações apuradas a respeito dos parâmetros físicos do modelo.

Pudar \& Liggett (1992) explicam que sistemáticas empenhadas em determinar vazamentos não substituem as mais tradicionais inspeções de campo, mas lhes servem de guia complementar. A detecção de vazamentos em redes de distribuição de água pode ser executada resolvendo um problema inverso, de minimização dos desvios entre valores observados e simulados de pressão e vazão. O problema é formulado supondo-se áreas de orifícios equivalentes de possíveis fendas desconhecidas. A minimização das diferenças entre energias medidas e calculadas produz uma solução por áreas e a qualidade dos resultados depende da localização das medidas. Uma matriz de sensibilidade é utilizada para se decidir onde fazer as medidas. Os autores concluíram que ambos, localização e magnitude dos vazamentos são sensíveis à quantidade e à qualidade das medidas de pressão.

Pudar \& Liggett (1992) afirmam que o mais popular procedimento de localização de vazamentos usa processo de escuta. A detecção de vazamentos pode ser feita como uma rotina ou quando há suspeitas de perdas maiores; devido a anormalidades nos dados, tais como um aumento na proporção de demanda de água entre a noite e o dia. Um simples método para detecção das perdas tem grande valor econômico. As atividades de escuta (geofones eletrônicos) mencionadas por Pudar \& Liggett (1992) foram utilizadas no trabalho aqui proposto, com o objetivo de eliminação de vazamentos grosseiros, antes de se proceder à calibração, incluindo vazamentos distribuídos ao longo dos condutos.

Mais recentemente, Savic \& Walters (1997) e Walters et al. (1998) aplicaram Algoritmos Genéticos (AGs), para determinar as rugosidades em redes de distribuição de água, obtendo bons resultados. Eles empregaram uma função objetivo básica para um problema de calibração de modelos de redes de distribuição de água em regime permanente da seguinte forma:

$$
\min _{k} f(H, Q)=p_{1} \sum_{i}\left(H_{i}^{0}-H_{i}^{p}\right)^{2}+p_{2} \sum_{j}\left(Q_{i}^{0}-Q_{j}^{p}\right)^{2}
$$

Onde: $\mathrm{p}_{1}$ e $\mathrm{p}_{2}$ são coeficientes normalizantes, $\mathrm{H}_{\mathrm{i}}{ }^{0}$ e $\mathrm{H}_{\mathrm{i}} \mathrm{P}$ são as cargas observadas e previstas para o nó i, respectivamente, e $\mathrm{Q}_{\mathrm{i}}{ }^{0}$ e $\mathrm{Q}_{\mathrm{i}} \mathrm{P}$ são os fluxos observado e previsto no tubo i.

Tucciarelli et al. (1999) propuseram a estimativa da perda de água em redes de distribuição através de um processo iterativo realizado em duas etapas. A primeira etapa consiste na estimativa dos parâmetros do modelo de simulação da rede. Essa estimativa é realizada através da minimização do somatório dos quadrados das diferenças entre os valores observados e calculados de carga hidráuli- 
ca e vazão, tendo como dados conhecidos o número de nós e as características principais da rede em questão como comprimentos e diâmetros. Dentre os parâmetros estimados estão o fator e o expoente de perda por vazamento, que correspondem à perda de água por unidade de área da tubulação relativa a cada área da rede. A segunda etapa corresponde à realização da otimização das aberturas das válvulas incluídas na rede, respeitando as pressões mínimas requeridas nos nós.

\section{ALGORITMOS GENÉTICOS}

Os Algoritmos Genéticos são provavelmente o tipo mais conhecido de programação evolucionária. Baseiam-se na seleção natural e genética populacional, onde são observados mecanismos como a sobrevivência e reprodução preferenciais dos indivíduos mais aptos da população, na manutenção de uma população com diversos membros, na herança de informação genética dos pais e na mutação ocasional dos genes.

A evolução natural ocorre nos cromossomos, que são elementos microscópicos das células nucleares os quais transmitem informações hereditárias através dos genes. De acordo com a terminologia dos AGs, um cromossomo (indivíduo ou solução), referido como string, caracteriza uma "cadeia representativa a solução do problema". Cada cadeia representativa de uma solução é formada por uma série de caracteres ou traços, análogos aos genes biológicos, representando as variáveis de decisão do problema através de códigos. Assim a população de cromossomos representa um conjunto de possíveis soluções do problema. Os AGs evoluem a partir de uma população inicial de soluções geralmente produzidas aleatoriamente. A aplicação repetida de operadores genéticos busca soluções eficientes para o problema em estudo, ou seja, aquelas com valores maiores para a função de aptidão são mantidas enquanto as de valores menores são descartadas. As vantagens dos AGs sobre os métodos de busca tradicionais incluem o fato de que eles retêm uma amostra "bem adaptada" da população, durante a busca do ótimo global. Tais algoritmos consideram regras probabilísticas de transição de um conjunto de soluções para outro, e tem a flexibilidade de admitir funções objetivo (ou de aptidão) complexas, descontínuas ou que não possuam derivadas.

Os AGs geralmente compreendem três operadores: reprodução, cruzamento (recombinação) e mutação. A reprodução é o processo através do qual cadeias representativas de soluções são copiadas para a próxima iteração de AG, de acordo com o valor da função de aptidão correspondente, através de um processo de seleção que privilegia a sobrevivência das melhores soluções. $\mathrm{Na}$ sua forma mais simples a recombinação realiza a troca parcial de segmentos correspondentes entre duas cadeias representativas de soluções "pais" produzindo duas cadeias representativas de soluções "filhos". A mutação é a degeneração ocasional dos valores, permitindo a introdução de novas características às populações.

A aplicação de AGs envolve a escolha apropriada do código de representação das variáveis de decisão do problema. Apesar das diversas possibilidades de codificação, Goldberg (1989) sugeriu que o desempenho dos AGs é ótimo quando a codificação binária é empregada. Entretanto muitos problemas requerem representações diferentes, incluindo a codificação em números reais para as variáveis de decisão.

Simpson et al. (1994), Mckinney \& Lin (1994), Reis et al. (1997) e Ritzel \& Eheart (1994) são exemplos de aplicações de AGs com sucesso para resolver problemas complexos na área de recursos hídricos. Outros trabalhos seguiram-se a estes, aplicando AGs, inclusive para realizar calibração de modelos de redes (Savic \& Walters, (1997) e Walters et al. (1998).

\section{DESCRIÇÃO DOS MÓDULOS DE OTIMIZAÇÃO UTILIZADOS}

O algoritmo de calibração de duas fases aqui proposto utiliza-se de dois procedimentos de busca direta via AGs codificados em Fortran, conforme descrito a seguir.

A-) Determinação de rugosidades dos trechos da rede (módulo 1 - Silva, 2003)

O problema inverso de determinação de parâmetros da rede, em termos das rugosidades dos trechos através da minimização dos desvios entre valores produzidos via simulação hidráulica e dados de pressão e vazão observados em campo, pode ser expresso através da maximização da seguinte função objetivo $(F . O)$ :

$F O=\left\{\sum_{k=1}^{C}\left\{\begin{array}{c}w_{H}{ }^{(k)} \cdot \sum_{i=1}^{N}\left[\frac{P_{\text {simi }}-P_{o b s i}}{\left(\sum_{i=1}^{N} P_{o b s i}\right) / N}\right]^{2}+ \\ w_{Q}{ }^{(k)} \cdot \sum_{j=1}^{M}\left[\frac{Q_{s i m j}-Q_{o b s j}}{\left(\sum_{j=1}^{M} Q_{o b s j}\right) / M}\right]^{2}\end{array}\right\}\right.$

sendo:

$P$ - carga de pressão (mH2O)

$Q$ - vazão (L/s)

$N$ - conjunto de pontos de observação de valores de pressão

$M$ - conjunto de pontos de observação de valores de vazão C - número de dias de observação 
$\mathrm{w}_{\mathrm{H}}, \mathrm{w}_{\mathrm{Q}}$ - pesos atribuídos aos desvios de pressão e vazão sim, obs - denotam valores simulados e observados, respectivamente.

Basicamente, a F.O. a ser maximizada constitui o inverso da soma dos quadrados das diferenças adimensionalizadas entre valores de pressões e vazões simulados e observados, multiplicados pelos respectivos pesos atribuídos a cada uma das grandezas, estes foram considerados de valor 1 , devido a estudos prévios realizados testando-se diversos valores.

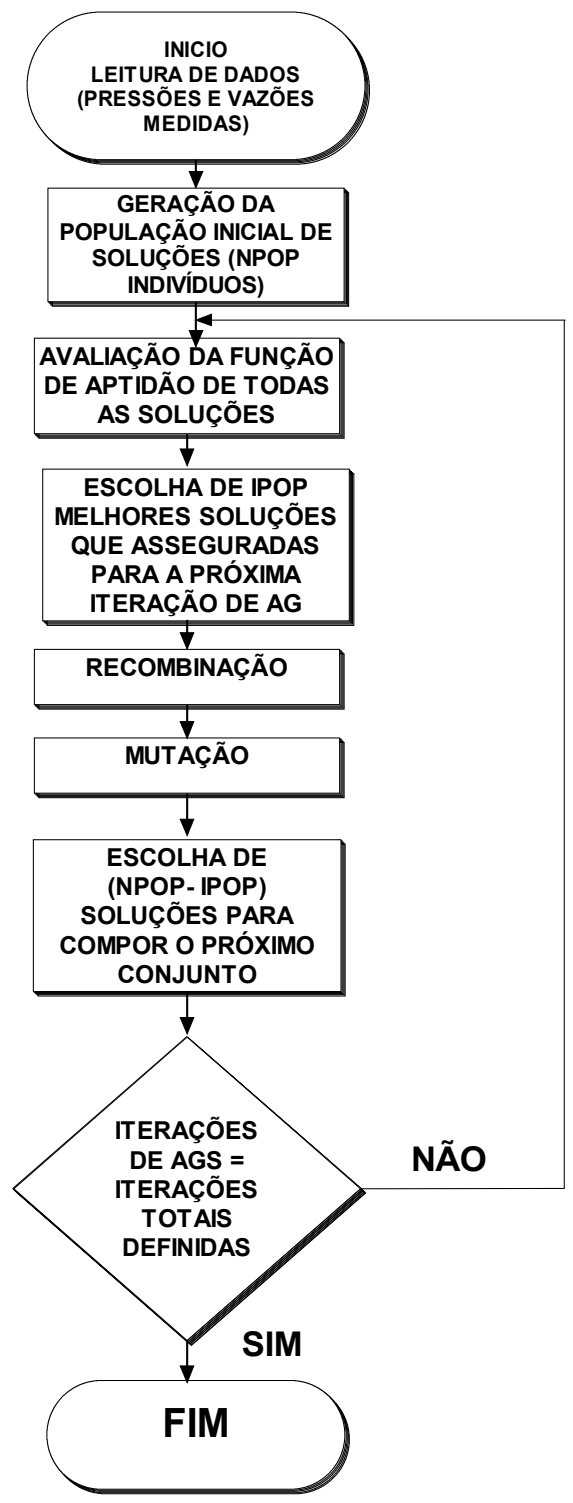

Figura 1 - Algoritmo para determinação das rugosidades utilizado por Silva (2003)

Os AGs geracionais foram utilizados, conforme vantagens apresentadas em estudos comparativos realiza- dos (Silva \& Reis, (2002)), destacando-se o maior número de soluções que se trabalha ao longo da evolução quando comparado com os AGs Steady State.

Os AGs geracionais com reprodução preferencial das melhores soluções (elitistas) (Figura 1) asseguram que um determinado número (IPOP) de melhores indivíduos de cada iteração sejam preservados na próxima. A população total de indivíduos de cada iteração de AG é submetida aos operadores genéticos de recombinação e mutação. Após estes operadores os NPOP-IPOP melhores indivíduos são selecionados e adicionados (Sub-rotina Seleção 2) aos IPOP indivíduos previamente escolhidos para compor os indivíduos da iteração seguinte. Tudo é repetido até que o número de iterações de AGs estipulado seja atingido.

\section{B-) Determinação dos parâmetros C1 e N1 relativos a vazamentos da rede (módulo 2 - Caliman et al. 2001)}

Baseado no trabalho de Caliman et al. (2001), a bibliografia apresenta diversos trabalhos (Germanopoulos e Jowitt , 1989; Jowitt e Xu 1990; Pezzinga, 1994; Reis et al. ,1997; Pezzinga e Gueli , 1998; Vairavamoorthy e Lumbers, 1998) que se utilizam modelos de vazamentos, sobre a localização otimizada de válvulas de controle de pressão, visando minimizar as perdas por vazamento, utilizando um modelo do tipo pressão x vazamento na forma:

$$
L=C 1 \cdot l \cdot P^{N 1}
$$

Sendo: $L=$ vazamento em $\mathrm{L} / \mathrm{s}, l=$ comprimento do trecho em $\mathrm{m}, P=$ carga de pressão média no trecho considerado em $\mathrm{mH}_{2} \mathrm{O}, \mathrm{C} 1$ e $\mathrm{N} 1$ os parâmetros relação vazamento x pressão.

A determinação dos parâmetros do modelo de vazamentos a partir de observações de campo, pode ser expresso através da minimização dos desvios entre os valores calculados pelo modelo de avaliação hidráulica e os correspondentes observados em campo, como:

$\underset{\mathrm{C} 1, \mathrm{~N} 1}{\operatorname{Min}} \sum_{i=1}^{n_{p o}}\left[\sum_{j=1}^{n_{n}} w_{h} \frac{\left|P_{i j O B S}-P_{i j S I M}\right|^{2}}{\left(\bar{P}_{\mathrm{OBS}}\right)^{2}}+\sum_{k=1}^{n_{c}} w_{q} \frac{\left|Q_{i k O B S}-Q_{i k S I M}\right|^{2}}{\left(\bar{Q}_{\mathrm{OBS}}\right)^{2}}\right]$

Essa é a função objetivo ou critério segundo o qual a aptidão de cada solução é avaliada, onde: $P_{i j S I M} \mathrm{e}$ $P_{i j \mathrm{OBS}}$ representam os valores de pressão simulada e observada, respectivamente, para o nó $j$ e padrão de observação $i$; $Q_{i k S I M} e Q_{i k O B S}$ representam os valores de vazão simulada e observada, respectivamente, para o conduto $k$ e padrão de observação $i$; $n_{n}$ representa o conjunto de nós de monitoramento dos valores de pressão; $n_{c}$ representa o conjunto 


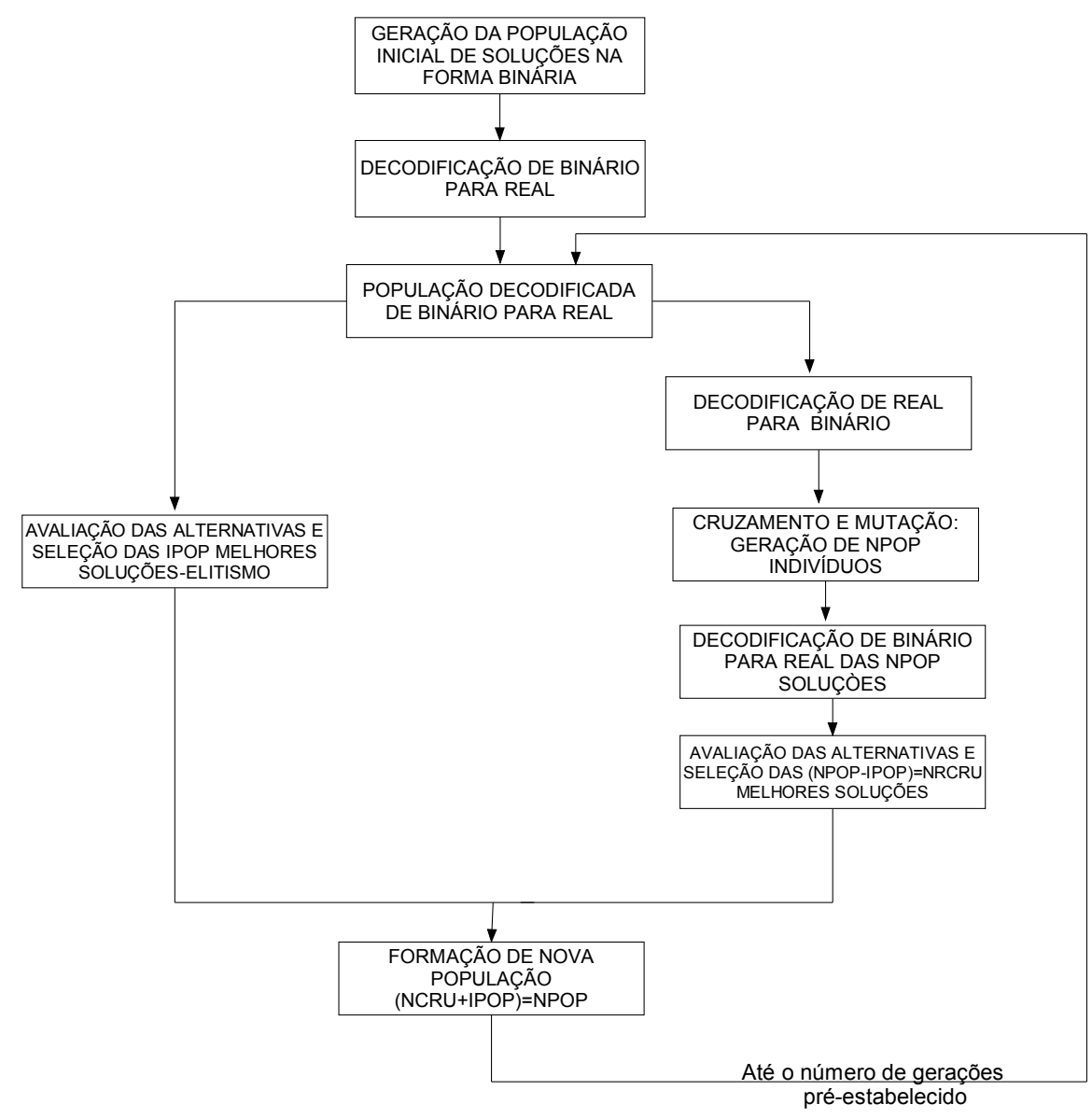

Figura 2 - Algoritmo para determinação dos parâmetros de vazamentos utilizado por (Caliman et al., 2001)

de condutos de monitoramento dos valores de vazão; $P_{O B S}$ é a média dos valores de pressão observados; $\bar{Q}_{O B S}$ é a média dos valores de vazão observados, $n_{p o}$ número de padrões de observação; $C 1$ e $N 1$ as variáveis de decisão do problema, que correspondem aos parâmetros do modelo pressão x vazamento (Equação (3)) e $w_{b}$ e $w_{q}$ são pesos atribuídos à importância relativa de minimização dos desvios entre os valores calculados e observados de carga hidráulica e vazão respectivamente, estes foram assumidos como 1, por a variabilidade do comportamento do sistema ser pequena devido os testes terem sidos realizados no período da madrugada.

Os dados de campo para o cálculo dos desvios são obtidos com base em testes noturnos realizados, mantendo fixa a pressão na entrada do setor em estudo em diversos níveis, através das manobras de registro existente, conforme reportado por Santos (2000). A partir do registro totalmente aberto, são realizadas manobras sucessivas de fechamento do mesmo, registrando simultaneamente as medidas de vazão e pressão na entrada do setor, e em pontos no interior da rede.

\section{MODELO HIDRÁULICO (2 módulos)}

A formulação do modelo hidráulico das redes geralmente envolve a equação da continuidade para cada nó da rede e equação da energia para cada trecho (ligação entre nós consecutivos), cuja solução é buscada através da técnica numérica de linearizações sucessivas proposta por Germanopoulos \& Jowitt (1989).

Fixados os níveis dos reservatórios e demandas nos nós, o referido método produz valores de vazões nos trechos e pressões nos nós da rede. Este método fornece uma solução pontual, ou seja, relativa à determinada condição instantânea.

A equação da continuidade para cada nó é expressa como: 


$$
\sum_{j \in j_{i}} Q_{i j}+C_{i}=0 ; \text { para todos os nós } i
$$

onde $\mathrm{Q}_{\mathrm{ij}}$ é a vazão no elemento hidráulico que conecta os nós i e j; $C_{i}$ é o consumo no nó i; e $J_{i}$ são todos os nós conectados ao nó i. O fluxo $\mathrm{Q}_{\mathrm{ij}}$ é positivo no sentido de $\mathrm{i}$ para j e é expressa através da fórmula universal.

Os vazamentos são relacionados com as pressões na rede, conforme expresso em (3). Autores como (Germanopoulos \& Jowitt, 1989) vem empregando tal expressão admitindo $\mathrm{N} 1=1,18$; conforme experimentos conduzidos na Inglaterra.

$$
S_{i, j}=c_{i} L_{i j}\left(P_{i j}^{a v}\right)^{N 1}
$$

onde: $\mathrm{S}_{\mathrm{i}, \mathrm{j}}$ é o vazamento da tubulação que liga os nós i e j; $c_{\mathrm{i}}$ é uma constante da rede; $\mathrm{L}_{\mathrm{ij}}$ é o comprimento do trecho limitado pelos nós i e j e $P_{i j}^{a v}$ é a pressão média ao longo do tubo. Assim, a equação (6) pode ser escrita diretamente em termos das cargas hidráulicas nos nós correspondentes conforme equação 7 .

$$
S_{i, j}=c_{i} L_{i j}\left[0,5\left(H_{i}-h_{i}+H_{j}-h_{j}\right)\right]^{N 1}
$$

onde $h_{i}$ e $h_{j}$ são respectivamente o nível do solo no nó i e j respectivamente. A equação (5) pode então ser reescrita como:

$$
\sum_{j \in j_{i}} Q_{i j}+C_{i}+0,5 \sum_{j \in j_{i}} S_{i j}=0
$$

para toda pressão no nó i.

onde: o vazamento $S_{\mathrm{ij}}$ é distribuído igualmente entre os nós i e j.

A determinação do valor da função de aptidão de cada alternativa de solução é feita através da "Sub-rotina Avaliador", que realiza avaliações hidráulicas utilizando o modelo hidráulico empregado por Reis \& Porto (1997), no qual o cálculo da perda de carga é feito pela fórmula universal. A avaliação hidráulica fornece, entre outras informações, valores de pressão e vazão respectivamente para cada nó e trecho da rede simulada, a partir de dados de entrada. Tais informações produzem um valor de aptidão para cada alternativa da população de determinada geração (iteração de $A G)$.

\section{PARTICULARIDADES DO AVALIADOR HI- DRÁULICO (MÓDULO 1)}

\section{Cálculo do fator de consumo}

A informação disponível para a calibração das redes geralmente inclui a vazão abastecida total ( $Q_{\text {entradasetor }}$, monitorada em campo. Entretanto, não se sabe do total de

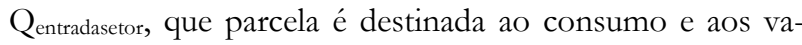
zamentos. Supondo-se que a distribuição espacial de demanda seja completamente conhecida e partindo do princípio que a vazão abastecida é composta de consumo e vazamentos, podemos escrever:

$$
\begin{aligned}
& \mathrm{Q}_{\text {ent setor }}=\text { Consumos } \\
& \text { setor } \\
& \text { onde: } \\
& \text { Consumo }_{\text {setor }}=\sum_{i=1}^{\text {nós }} \text { Consumo }_{i}
\end{aligned}
$$

$$
\text { Vazamentos }_{\text {setor }}=\sum_{j=1}^{\text {trechos }} \text { vazamentos }_{j}
$$

Um fator multiplicador das demandas denominadas de referência é utilizado para expressar a variação do consumo das horas do dia, de forma que:

$$
\text { Consumo }_{i}=\text { fator } \times C_{\text {referência }}{ }_{i}
$$

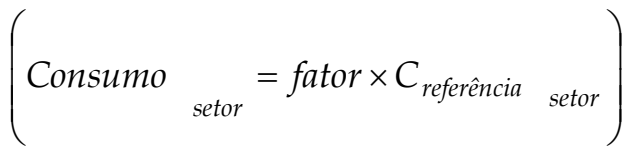
sendo i os nós da rede

$$
C_{\text {referência setor }}=\sum_{i=1}^{\text {nós }} c \text { referência } i
$$

C referência é o consumo de referência, estabelecido com base no consumo mensal médio por quadra do setor, distribuído aos nós de acordo com as áreas de influência dos mesmos.

A substituição de (12) em (9) produz: 


$$
\text { fator }=\frac{Q_{\text {entrada setor }}-\text { vazamentos }}{\text { setor }}
$$

A Figura 3 mostra que o fator é reavaliado iterativamente até que a convergência para determinado valor seja atingida. O processo iterativo inicia-se com o vazamento nulo. Com o fator calculado determina-se $Q_{K}$ e QsK (que representam respectivamente a vazão e vazamento nos trechos para o passo k).

Permite-se então que se avalie a parcela da $Q_{\text {entra- }}$ dasetor atribuída ao vazamento.

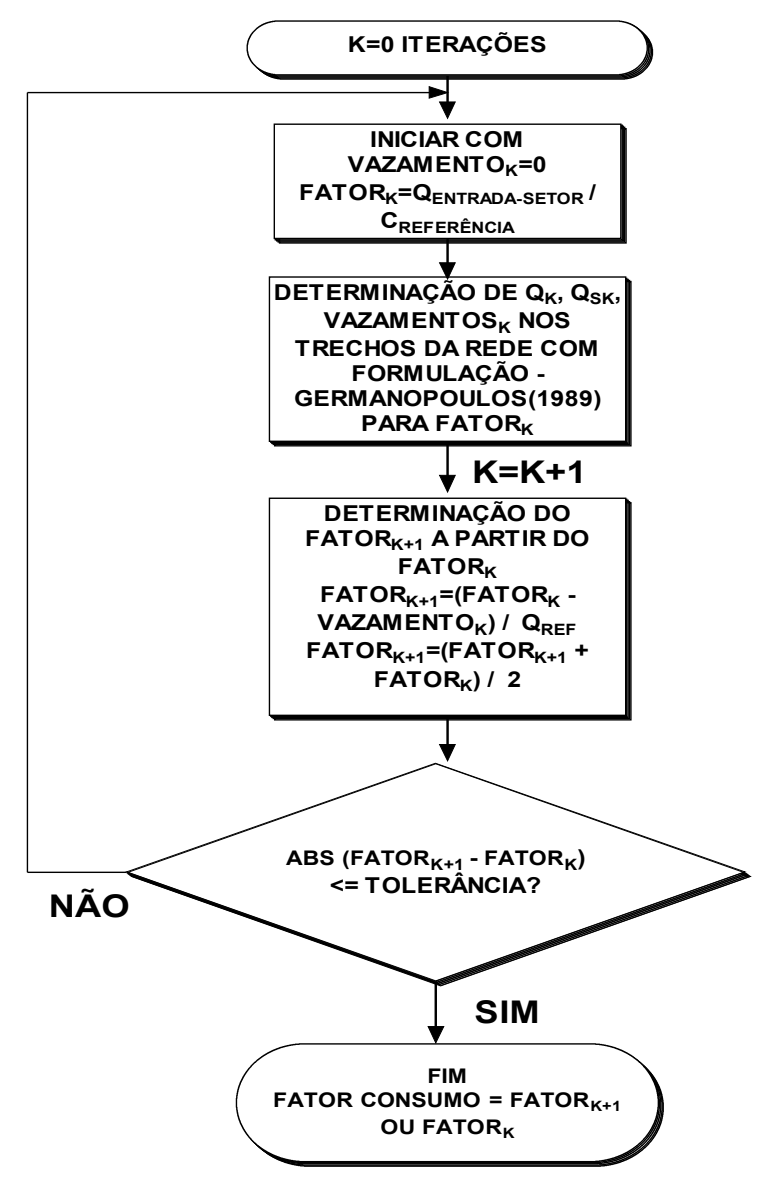

Figura 3 - Módulo de cálculo de fator de demanda

\section{ALGORITMO DE DOIS PASSOS UTILIZADO}

Constatou-se, ao longo de estudos realizados, que a calibração dos parâmetros da rede (rugosidades dos trechos) e parâmetros do modelo de vazamentos, conjuntamente, produz resultados mais consistentes que a calibração de somente um parâmetro. Utilizou-se a rotina do módulo 2, elaborada por Caliman et al. (2001), para deter- minação dos parâmetros $\mathrm{C} 1$ e $\mathrm{N} 1$ da relação pressão x vazamento, conforme o procedimento descrito na Figura 2. Para determinação das rugosidades dos trechos fez-se o uso da rotina utilizada por Silva (2003), Figura 1.

Conforme o procedimento de duas fases, ilustrado na Figura 4, utilizando os valores C1 e N1 da literatura, determinam-se as rugosidades (rotina de Silva (2003)). Novos valores de C1 e N1 são obtidos (rotina Caliman et al. (2001)). A partir destes últimos, recalculam-se as rugosidades dos trechos da rede. O procedimento é repetido até que $\mathrm{C} 1$ e N1 tenham seus valores próximos de C1 e N1 anteriores.

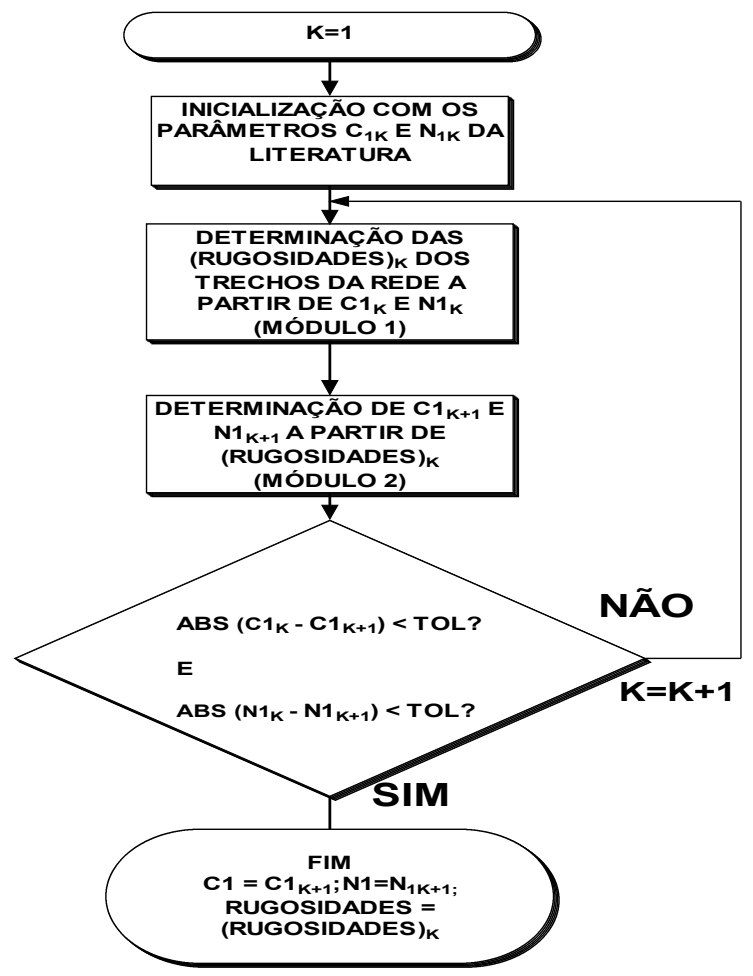

Figura 4 - Algoritmo de dois passos utilizado

\section{PROCEDIMENTO GERAL DE CALIBRAÇÃO DE MODELOS DE REDES DE DISTRIBUI- ÇÃO DE ÁGUA}

As técnicas e procedimentos para construir os modelos de simulação de sistemas de distribuição de água podem ser resumidos nas seguintes atividades:

(i) Consulta às informações do sistema de distribuição de água, tais como: registros dos consumidores e mapas, entre outras informações; (ii) Inspeção do local para instalação de equipamentos; (iii) Medidas de campo preliminares; (iv) Exercício de medida de campo;(v) Entrada de dados da rede para uma análise de computador; e (vi) Calibração do modelo. 
O objetivo básico da consulta às informações é selecionar dados da rede que podem ser justificadamente incluídos no modelo. Estas informações foram obtidas junto ao SAAE - São Carlos. A inspeção dos locais para a instalação dos equipamentos é fundamental pois o monitoramento depende de condições especiais para a sua viabilidade.

Vale destacar que normalmente a maior fonte de erro na modelagem de sistemas de distribuição de água está relacionada à incerteza na estimativa do uso da água. Tal fato se deve às variações de consumo serem descontínuas durante horas do dia, os dias da semana, as estações do ano e os ciclos de longo prazo.

A distribuição espacial dos consumos foi avaliada a partir de dados de consumos mensais, relativos às quadras do setor de acordo com os registros de SAAE - São Carlos.

Os exercícios de medidas de campo são então descritos a seguir.

\section{LEVANTAMENTOS DE CAMPO}

Os levantamentos de campo foram realizados por autores do trabalho e as etapas de trabalhos de campo basicamente consistiram em: detecção e reparos de vazamentos grosseiros, testes noturnos de vazamentos e monitoramento contínuo de pressões e vazões.

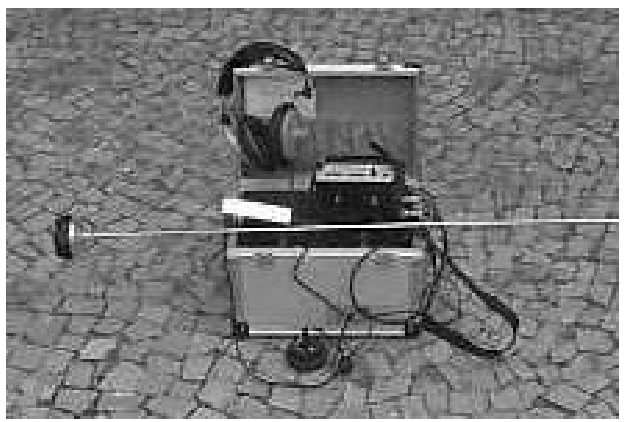

Figura 5 - Geofone Haste de escuta

\section{Detecção e reparos de vazamentos grosseiros da área de estudo}

Os vazamentos podem ser divididos em "inerentes" e "grosseiros". Os inerentes são pequenos vazamentos provocados por falhas nas junções, por exemplo, e os vazamentos "grosseiros" são grandes fendas na tubulação ocasionadas por falhas mecânicas, que normalmente são comunicados aos órgãos responsáveis e reparados.

Com o propósito de eliminação dos vazamentos grosseiros não previstos no modelo, a equipe de alunos do projeto realizou o "geofonamento" da área para detecção e posterior reparo de vazamentos grosseiros, conforme mostrado na Figura 5.

\section{Testes noturnos}

Os testes noturnos foram realizados para a determinação da curva Pressão x Vazamento.

Instalados os medidores de pressão e vazão nos pontos de interesse da rede, realizaram-se manobras de fechamento gradual do registro (válvula) situado na entrada do setor. O período escolhido para a realização dos testes foi a madrugada, período em que considera que a demanda é desprezível e o consumo se deve praticamente aos vazamentos.

A Figura 6 ilustra a variação da pressão ao longo dos ensaios para um dos pontos de monitoramento.

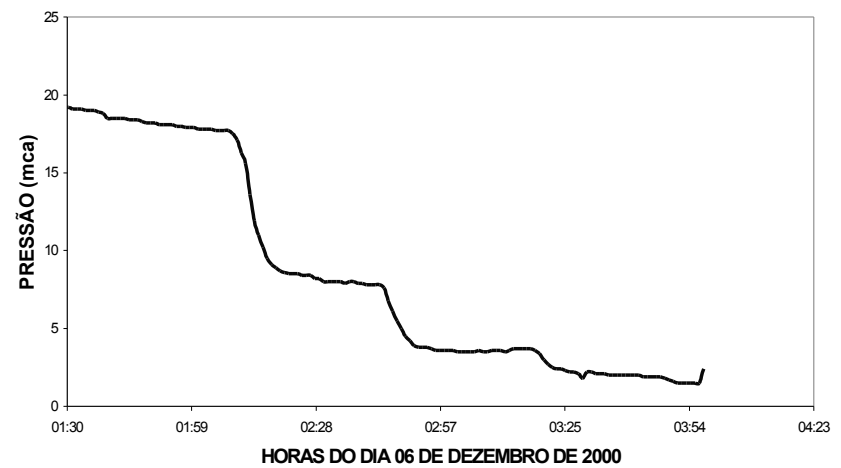

Figura 6 - Variação da pressão com as manobras realizadas no registro da entrada do setor em um dos dias do ensaio

\section{Testes contínuos}

A disponibilidade de equipamentos de medida de pressão e vazão foi limitada, no caso, a 8 e 2 unidades, respectivamente. Com o objetivo de ampliar as informações sobre o comportamento do sistema, reduzindo, conseqüentemente, o grau de indeterminação do problema, foi adotada a sistemática de rodízio de pontos de monitoramento, ou seja, foram coletados 5 conjuntos de dados de pressão em nós distintos. Embora cada conjunto tivesse sido monitorado durante intervalos de tempo distintos na escala de tempo, admite-se que eles sejam complementares entre si.

Pressão: As medidas de pressão foram feitas nos cavaletes residenciais, conforme ilustração da Figura 7. Foram utilizados oito medidores armazenadores de dados tipo Metro$\log N A$ da Technolog (o manual do equipamento indica a 
precisão de $0,10 \%$ da faixa, aferições com medidor confiável confirmou a qualidade do equipamento), para medir e armazenar dados de pressão.

Testes de vazão: As medidas de vazão foram feitas com medidores de vazão ultra-sônicos não intrusivos modelo Porta Flow 300 da Micronics (precisão de $1 \%$ ou $0,02 \mathrm{~m} / \mathrm{s}$, Figura 8). A aferição dos equipamentos de pressão e vazão foi realizada tendo como referência equipamentos do Laboratório de Hidráulica e Saneamento da Escola de Engenharia de São Carlos - USP.

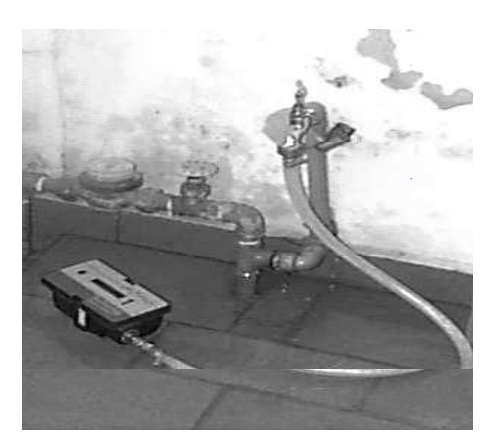

Figura 7 - Instalação de medidor Metrolog em cavalete residencial

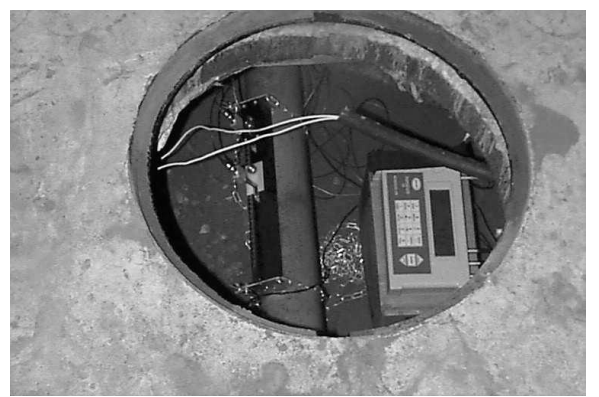

Figura 8 - Régua contendo sensores instalada na tubulação e módulo de aquisição de dados do medidor de vazão Portaflow 300 da Micronics

\section{ESTUDO DE CASO: SUB-SETOR "SÃO CARLOS 3" DA CIDADE DE SÃO CARLOS, - S.P.}

O procedimento de calibração exposto foi aplicado ao Sub-setor "São Carlos 3" de 146 nós e 193 condutos, existente na cidade de São Carlos-S. P. Trata-se de um setor isolável, abastecido por gravidade através de reserva- tório único, ao longo de uma extensão aproximada de $23060 \mathrm{~m}$, com tubulação em sua maior parte de P.V.C, com cotas topográficas variando de 836,50 a $873,00 \mathrm{~m}$, com um total de 2052 ligações, em sua maioria prediais (Dezembro de 2000), servindo uma população de aproximadamente 10000 habitantes.

\section{IMPLEMENTAÇÃO DOS AGS}

\section{A-) Representações das soluções}

\section{A-1) Módulo 1}

O problema de calibração foi posto como de determinação das rugosidades dos trechos da rede. Visando reduzir o número de variáveis de decisão do problema, as tubulações foram agrupadas em setores de acordo com as características idade e material que influenciam diretamente as rugosidades.

Além disso, permitiu-se um número prédeterminado de trechos com valores de rugosidades superiores aos dos setores a que pertencem, representando a presença de acessórios tais como válvulas. Para melhor guiar a busca desses acessórios, foram atribuídas probabilidades de existência de acessórios aos trechos, em conformidade com as informações contidas nos registros da companhia de abastecimento de água, inspeções de campo e contato com pessoas dos setores competentes. Tais probabilidades foram utilizadas tanto na geração das populações iniciais de soluções como pelo operador de mutação.

O respectivo problema apresenta como variáveis de decisão rugosidades e localização de trechos dotados de acessórios ou singularidades que promovem perda de carga localizada.

Em conformidade com o esquema da Figura 10, cada possível solução para o problema em estudo foi representada por uma cadeia de números reais, representativos das rugosidades dos setores da rede (no caso, dois). Além das rugosidades dos setores, as cadeias representativas de soluções são compostas da localização de $\mathrm{n}$ trechos da rede, com os respectivos valores de rugosidades, superiores aos atribuídos aos setores a que pertencem, sugerindo a existência de acessórios, ou outros elementos que provoquem perda de carga localizada. A quantidade de acessórios foi definida com base em informações cadastrais fornecidas pelo serviço de água local e restrita a $n=23$ (Figura 10).

Assim, cada solução totaliza 48 variáveis de decisão. A faixa de variação das rugosidades foram adotadas com base na idade e tipo de materiais da rede de acordo com Porto(1998).

De acordo com a sistemática de rodízio para monitoramento, foram obtidos 40 medidas de pressão e 10 de vazão. 


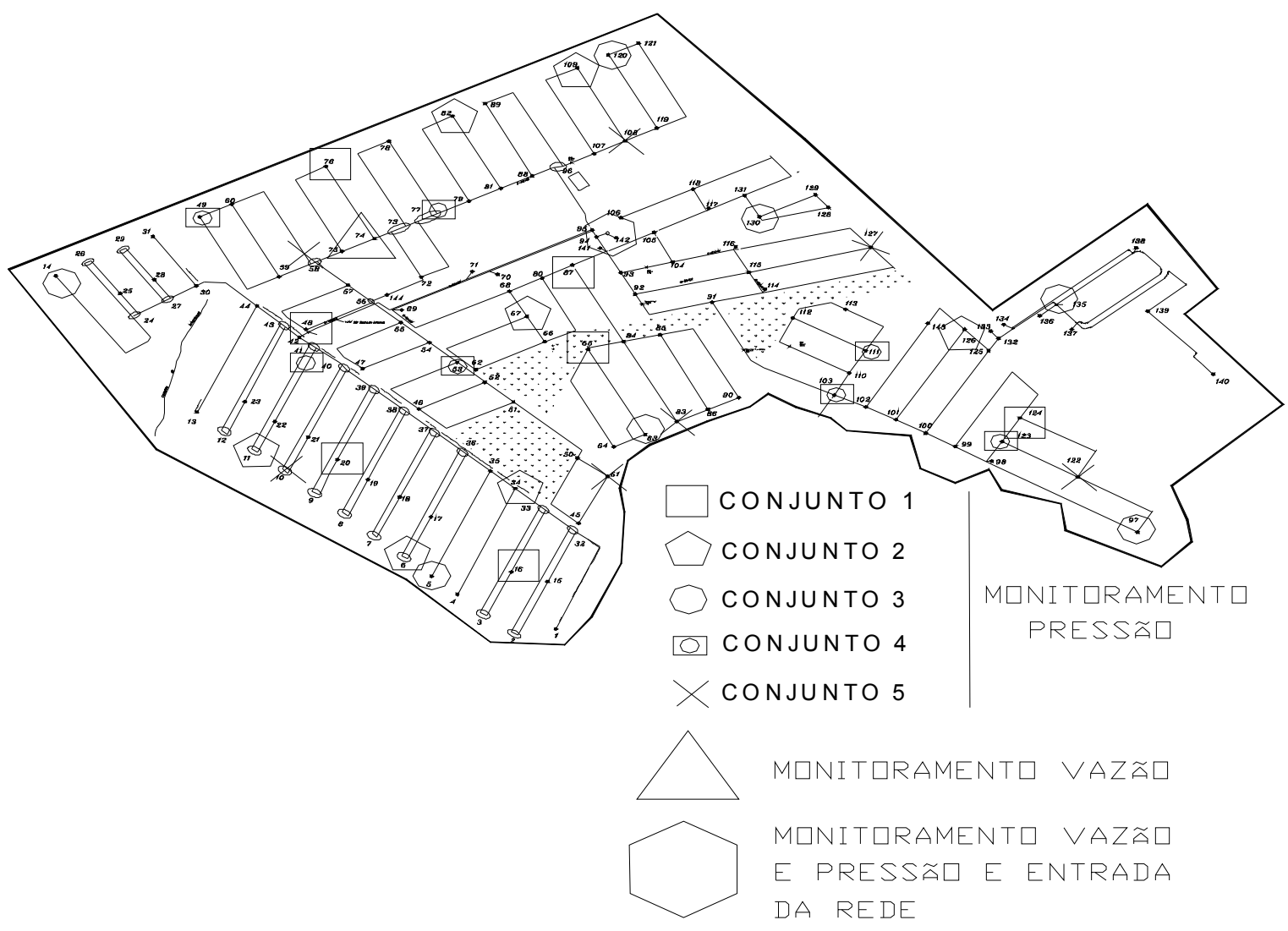

Figura 9 - Esquema da rede em estudo - Sub-Setor "São Carlos 3" da Cidade de São Carlos, S.P, Brasil com locação dos pontos de monitoramento

\section{A-2) Módulo 2}

O módulo computacional 2 realiza a determinação da constante C1 e do expoente N1 (equação 3), para 3 áreas da rede, delimitadas principalmente pela incidência de vazamentos.

Desta forma, na Figura 11, define-se a representação das soluções do problema.

\begin{tabular}{|c|c|c|c|c|c|c|}
\hline $\begin{array}{l}\text { Rugosid } \\
\text { Setor }\end{array}$ & $\begin{array}{l}\text { Rugosidade } \\
\text { Setor } 2\end{array}$ & & &... & $\begin{array}{l}\text { Localizaćão } \\
\text { Acessário n }\end{array}$ & $\begin{array}{l}\text { Rugosidade } \\
\text { Acessório n }\end{array}$ \\
\hline
\end{tabular}

Figura 10 - Cadeia representativa de solução -Módulo 1

\begin{tabular}{|c|c|c|c|c|c|}
\hline $\mathrm{Cl}$ & $\mathrm{N} 1$ & $\mathrm{Cl}$ & $\mathrm{N} 1$ & $\mathrm{Cl}$ & $\mathrm{N1}$ \\
AREA 1 & ÁREA 1 & ÁREA2 & ÁREA2 & ÁREA3 & ÁREA3 \\
\hline
\end{tabular}

Figura 11 - Cadeia representativa de solução-Módulo 2

\section{B-) Operadores e parâmetros adotados}

Dentre as diversas possibilidades de implementação dos AGs, no presente estudo foram adotadas as seguintes características:

- Geração da população inicial de soluções: uma população inicial de NPOP indivíduos é gerada aleatoriamente;

- Tamanho da população (NPOP): Com base em referências tais como SIMPSON et al. (1994) foi adotada uma população de 30 indivíduos;

- Tipo de AG: geracional elitista para o qual o número de iterações de AGs manteve-se fixa;

- Utilizou-se a técnica de substituição com elitismo para seleção dos indivíduos;

\section{$\underline{\text { Diferenças entre os módulos }}$}

\section{- Recombinação:}

Módulo 1: simples de dois pontos, com probabilidade de $95 \%$; 
Tabela 1 - Valores de C1 e N1 e função de aptidão para cada área da rede

POPULAÇÃO ALEATÓRIA 1

\begin{tabular}{lccccccc}
\hline & F.O & \multicolumn{2}{c}{ ÁREA 1 } & \multicolumn{2}{c}{ ÁREA 2 } & \multicolumn{2}{c}{ ÁREA 3 } \\
\hline & & C1x10E5 & N1 & C1x10E5 & N1 & C1x10E5 & N1 \\
ITERAÇÃO 1 & 24,11 & $1,6 / /$ & 0,627 & $\gamma, 1 /$ Y & 0,654 & $\gamma, 55 /$ & 0,547 \\
ITERAÇÃO 2 & 24,20 & 0,912 & 0,576 & 6,815 & 0,625 & 7,625 & 0,750 \\
ITERAÇÃOO 3 & 25,02 & 0,912 & 0,576 & 6,815 & 0,625 & 7,625 & 0,750 \\
\hline
\end{tabular}

POPULAÇÃO ALEATÓRIA 2

\begin{tabular}{lccccccc}
\hline & F.O & \multicolumn{2}{c}{ ÁREA 1 } & \multicolumn{2}{c}{ ÁREA 2 } & \multicolumn{2}{c}{ ÁREA 3 } \\
\hline & & C1x10E5 & N1 & C1x10E5 & N1 & C1x10E5 & N1 \\
ITERAÇÃO 1 & 23,55 & 1,026 & 0,600 & 7,070 & 0,621 & 6,252 & 0,801 \\
ITERAÇÃA 2 & 22,97 & 2,179 & 0,529 & 2,390 & 0,758 & 7,537 & 0,848 \\
ITERAÇÃA 3 & 23,83 & 1,026 & 0,600 & 6,789 & 0,621 & 6,252 & 0,801 \\
ITERAÇÃA 4 & 23,89 & 1,026 & 0,600 & 6,789 & 0,621 & 6,252 & 0,801 \\
\hline
\end{tabular}

POPULAÇÃO ALEATÓRIA 3

\begin{tabular}{lccccccc}
\hline & F.O & \multicolumn{2}{c}{ ÁREA 1 } & \multicolumn{2}{c}{ ÁREA 2 } & \multicolumn{2}{c}{ ÁREA 3 } \\
\hline & & C1x10E5 & N1 & C1x10E5 & N1 & C1x10E5 & N1 \\
ITERAÇÃOO 1 & 23,97 & 1,440 & 0,574 & 6,578 & 0,617 & 7,818 & 0,742 \\
ITERAÇÃO 2 & 24,45 & 1,440 & 0,574 & 6,578 & 0,617 & 7,818 & 0,742 \\
\hline
\end{tabular}

Módulo 2: simples de dois pontos, com probabilidade de $100 \%$;

- Mutação:

Módulo 1: uniforme por gene, com probabilidade de 2,1\% (1/número de genes, no caso $1 / 48)$ de acordo com Schaetzen (2000);

Módulo 2: uniforme por gene, com probabilidade de $5 \%$

\section{RESULTADOS E DISCUSSÃO}

Inicialmente avalia-se a função de aptidão das rotinas de determinação de rugosidades e parâmetros de vazamentos da rede.

A Figura 12 mostra que a função de aptidão de Silva (2003) tende a decrescer ao longo das simulações, ao passo que o desenvolvimento da curva de Caliman et al. 2001 (Figura 2) aparenta um crescimento com o aumento das iterações.

A Tabela 1 mostra a evolução dos valores desenvolvimento dos valores de C1 e N1 para as simulações realizadas a partir de três populações aleatórias de soluções distintas.

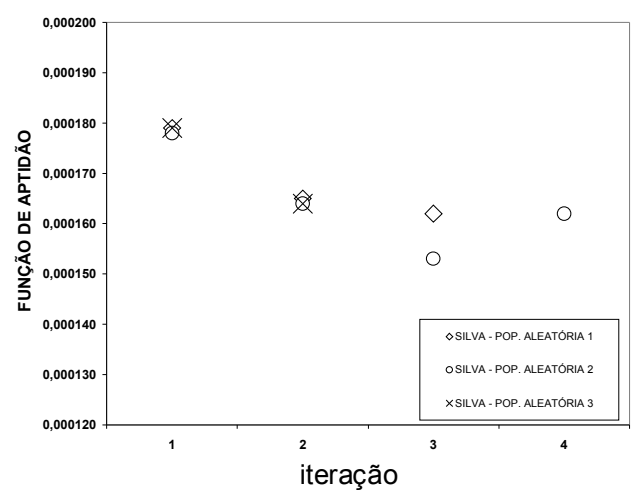

Figura 12 - Evolução da função de aptidão para rotina de Silva (2003)

Os parâmetros C1 e N1 foram avaliados para 3 áreas. Cada área foi definida por possuir características comuns relacionadas a vazamentos.

Observa-se que para a população aleatória 1 , os valores de C1 e N1 para todas as áreas não variam a partir da iteração 3 . 
A convergência ocorre a partir da iteração 4, para a população aleatória de soluções 2 e na iteração 2 para a população aleatória 3 .

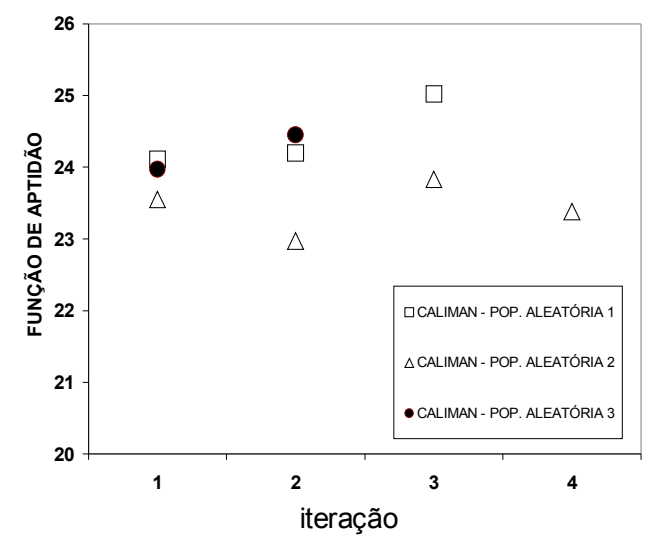

Figura 13 - Evolução da função de aptidão para rotina de Caliman et al. (2001)

Existe consistência nos valores de C1 e N1 obtidos, pois eles apresentam valores próximos para as simulações realizadas a partir de populações iniciais aleatórias distintas analisadas.

Nas Figuras 14, 16 e 18 são indicadas as rugosidades dos trechos considerados dotados de acessórios com maiores frequências ao longo das simulações. $\mathrm{Na}$ maioria dos trechos as oscilações que ocorrem ao longo das simulações são pequenas, com exceção dos pontos 132 (Figura 14 e 16) e 128 (Figura 18), que parecem ser ajustados somente mais bruscamente na última iteração.

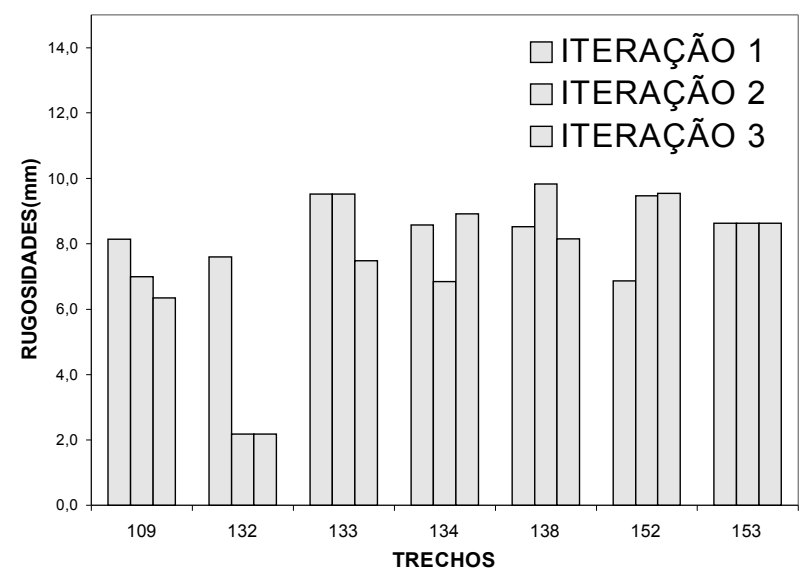

Figura 14 - Rugosidades dos trechos atribuídas a acessórios (rotina Silva (2003)) - população aleatória 1

Nas Figuras 15, 17 e 19 são apresentados os valores das rugosidades dos setores para diversas populações aleatórias. Observa-se que as rugosidades oscilam pouco ao longo das iterações, sendo que a variação maior ocorre no setor 2 .

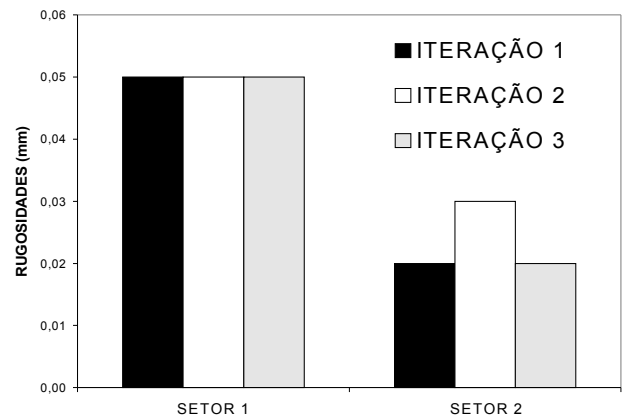

Figura 15 - Rugosidades dos trechos atribuídos aos setores (rotina Silva (2003)) - população aleatória 1

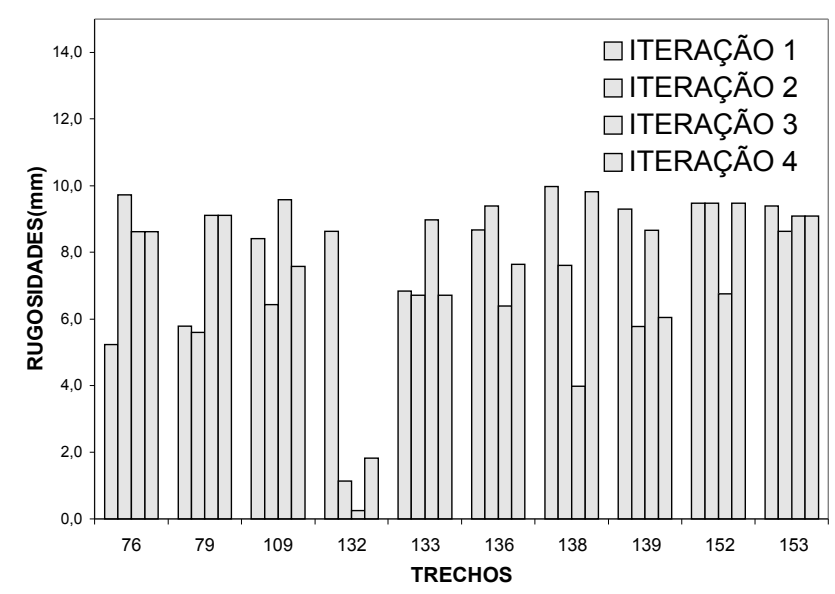

Figura 16 - Rugosidades dos trechos atribuídas a acessórios (rotina Silva (2003)) - população aleatória 2

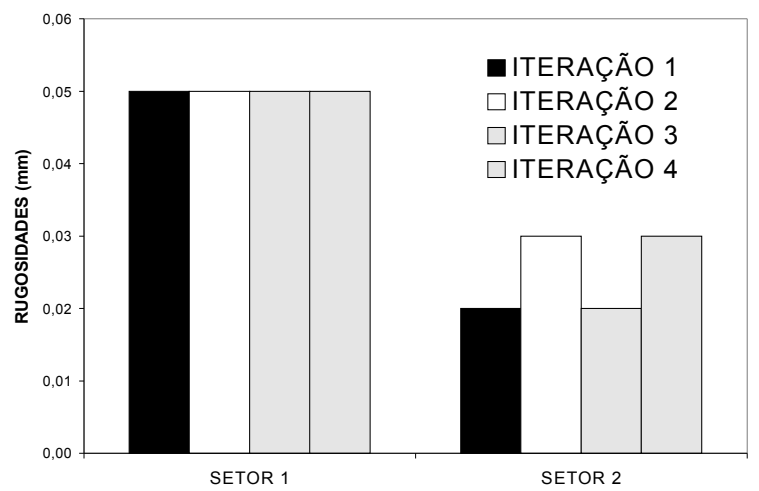

Figura 17 - Rugosidades dos trechos atribuídas aos setores (rotina Silva (2003)) - população aleatória 2 


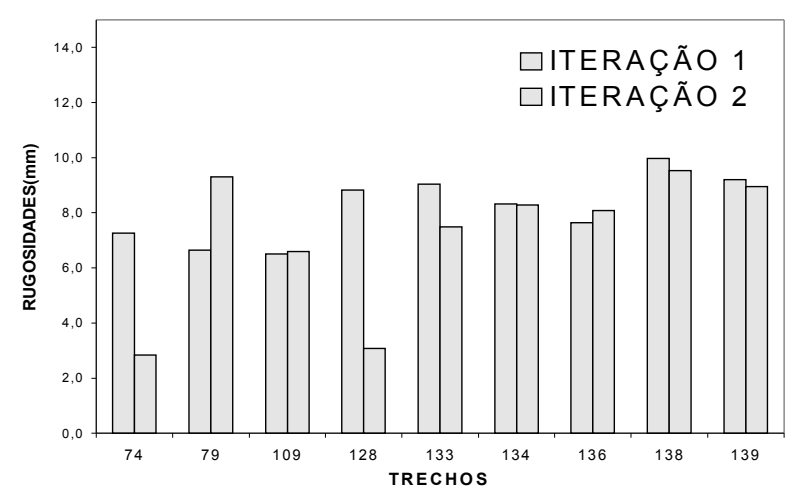

Figura 18 - Rugosidades dos trechos atribuídas a acessórios (rotina Silva (2003)) - população aleatória 3

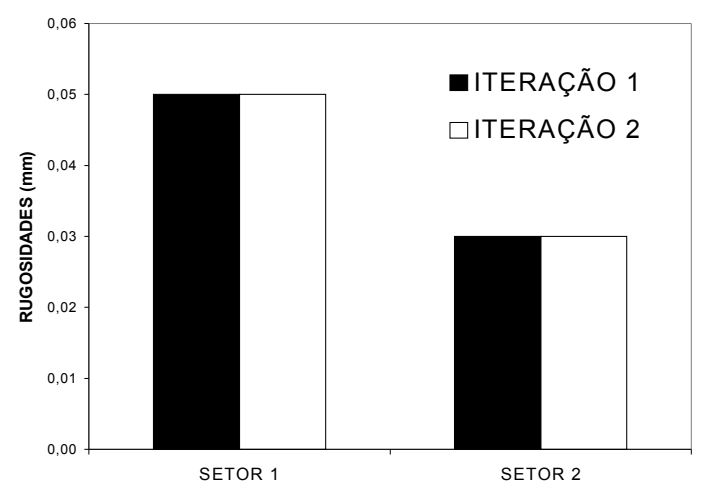

Figura 19 - Rugosidades dos trechos atribuídas aos setores (rotina Silva (2003)) - população aleatória 3

Embora o presente trabalho apresente apenas os resultados relativos aos ensaios sobre 3 populações iniciais aleatórias de soluções distintas, eles foram confirmados por Silva (2003), através de ensaios realizados a partir de 10 populações aleatórias.

A análise de frequência apresentada na Figura 20, demonstra que dos 23 acessórios (trechos com rugosidades maiores que as atribuídas aos setores da rede) previstos no modelo, 18 foram localizados com frequência acima de $75 \%$.

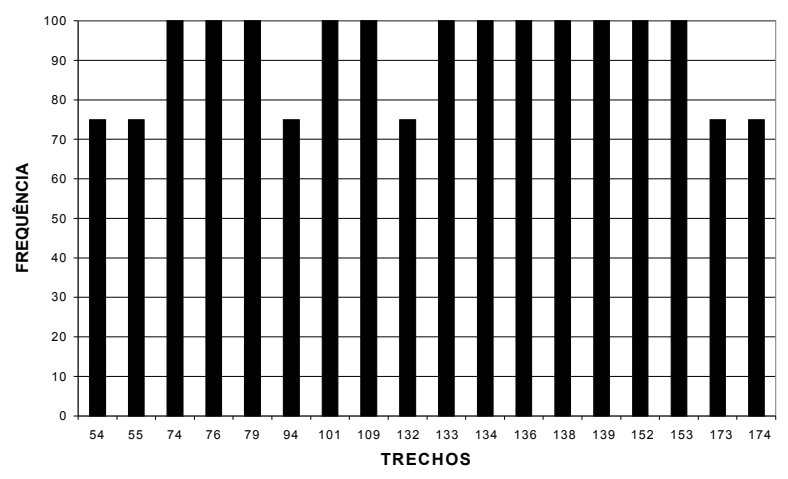

Figura 20 - Frequência de valores de rugosidades com valores acima dos atribuídos aos setores (rotina Silva (2003))
Nas Figuras 21 a 23, são comparados os valores obtidos através da rotina de Caliman et al. (2001) para as pressões medidas e simuladas para as 3 condições de demanda e para todas as iterações realizadas.

Somente são apresentados os resultados relativos à primeira população aleatória de soluções, pois para todas as populações o resultado obtido tem valores que se aproximam uns dos outros.

Nota-se que de forma geral os valores de pressão simulados estão muito próximos dos medidos para as diferentes condições de demanda.

Ao longo das iterações a variação também é muito pequena.

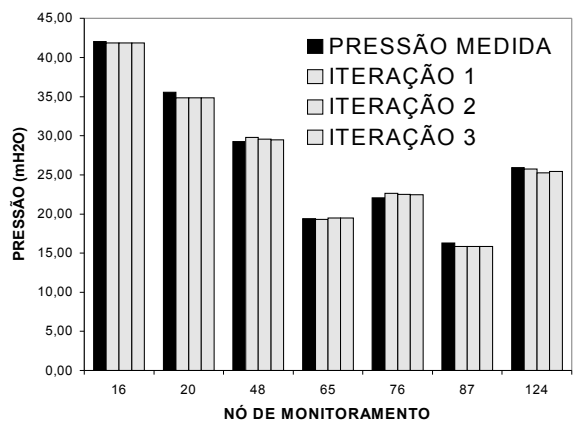

Figura 21 - Pressões medidas e simuladas para iterações do método - demanda máxima

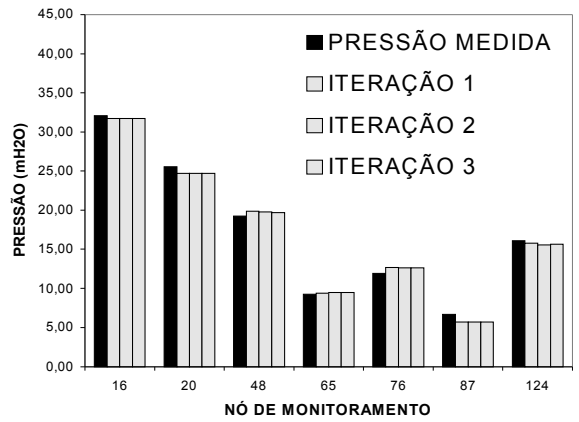

Figura 22 - Pressões medidas e simuladas para iterações do método - demanda média

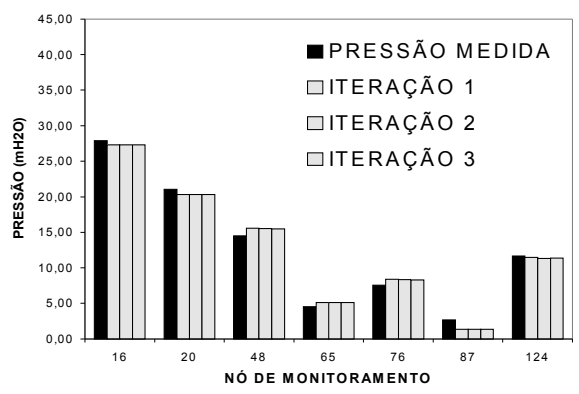

Figura 23 - Pressões medidas e simuladas para iterações do método - demanda mínima 
As Figuras 24 a 28 comparam pressões medidas e simuladas pela rotina do módulo 1. Da mesma forma que na análise anterior, os resultados são da primeira população aleatória e de forma geral os valores simulados para todas as iterações se aproximam muitos dos valores medidos. Também são poucas as oscilações observadas ao longo das iterações.

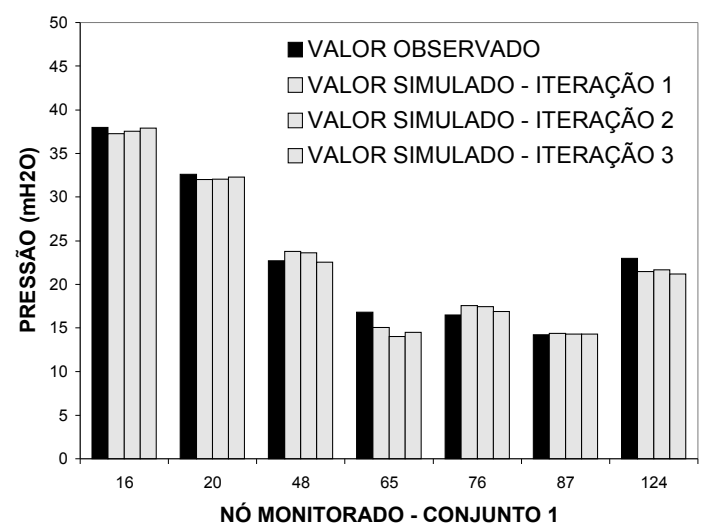

Figura 24 - Pressões medidas e simuladas para iterações do método - conjunto 1

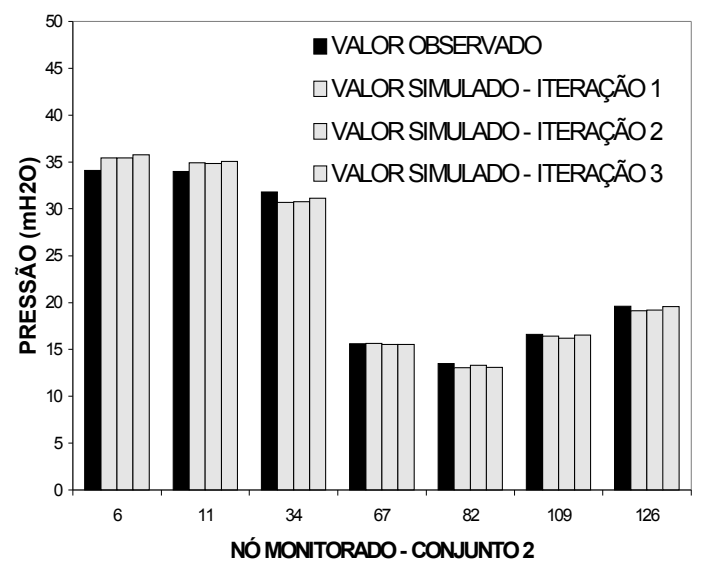

Figura 25 - Pressões medidas e simuladas para iterações do método - conjunto 2

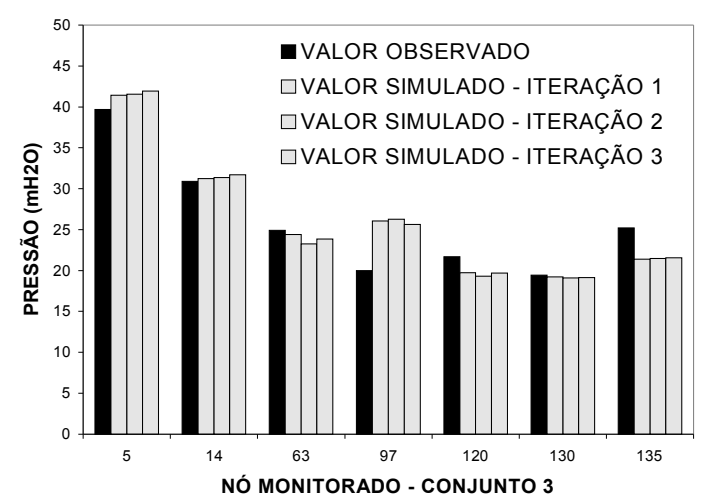

Figura 26 - Pressões medidas e simuladas para iterações do método - conjunto 3

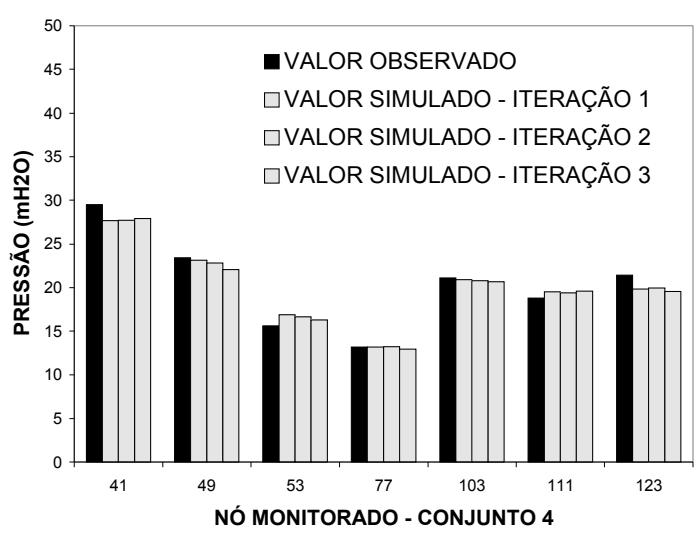

Figura 27 - Pressões medidas e simuladas para iterações do método - conjunto 4

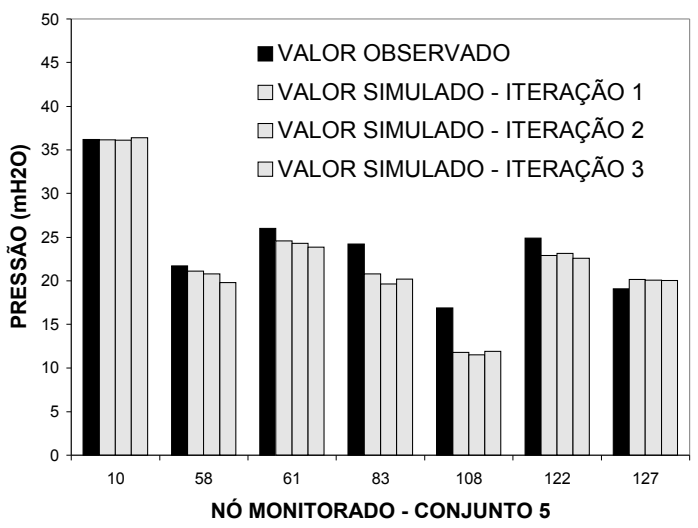

Figura 28 - Pressões medidas e simuladas para iterações do método - conjunto 5

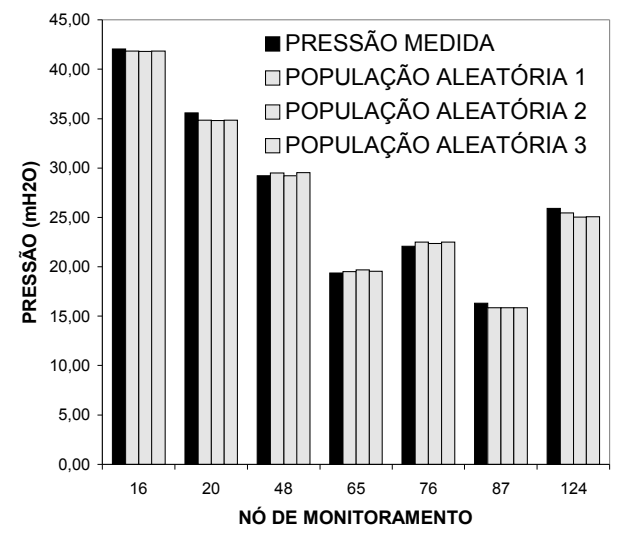

Figura 29 - Pressões medidas e simuladas para todas as populações aleatórias - condição de demanda máxima (rotina Caliman et al. 2001) 


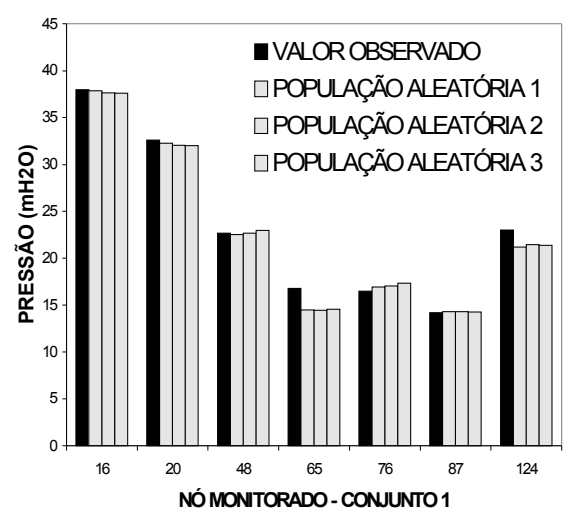

Figura 30 - Pressões medidas e simuladas para todas as populações aleatórias - conjunto 1 (rotina Silva (2003))

Nas Figuras 29 e 30 são apresentados os resultados da análise das pressões para os dois módulos, porém em termos de todas as populações aleatórias avaliadas. Tomou-se para a análise apenas um conjunto de pontos e uma condição de demanda, pela homogeneidade dos resultados. Para ambas as rotinas a aproximação dos valores, na maioria dos pontos simulados e medidos de pressão atende os critérios internacionalmente aceitos, o mesmo ocorrendo posteriormente para as informações de vazão.

Nas Figuras 31 a 33, são comparados valores de vazão obtidos da rotina de Silva (2003). Nestas figuras, mostra-se a comparação feita para todos os conjuntos de pontos e iterações. Dos dois pontos de monitoramento de vazão, um localizou-se na entrada do setor e outro no interior da rede. Observa-se que, para todos os conjuntos e pontos, os valores simulados tendem a se aproximar dos valores medidos. A Figura 34 mostra estes resultados para todas as populações aleatórias.

A boa aproximação de valores simulados e medidos de vazão ocorre também para o módulo 2 (Caliman et al. , 2001, Figura 35).

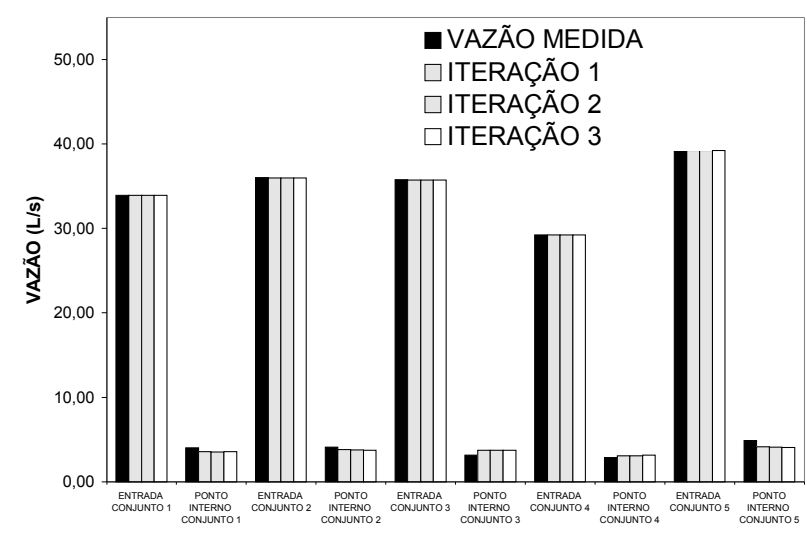

Figura 31 - Vazões medidas e simuladas para todas a população aleatória 1 (rotina Silva (2003))

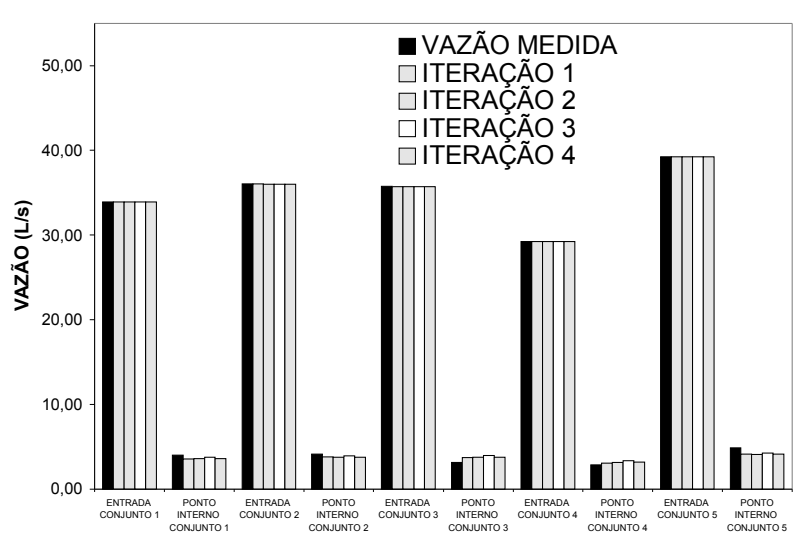

Figura 32 - Vazões medidas e simuladas para a população aleatória 2 (rotina Silva (2003))

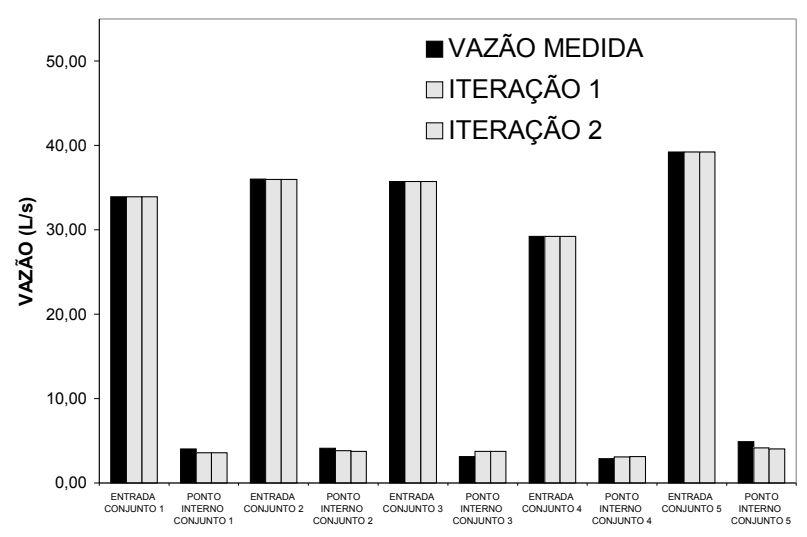

Figura 33 - Vazões medidas e simuladas para a população aleatória 3 (rotina Silva (2003))

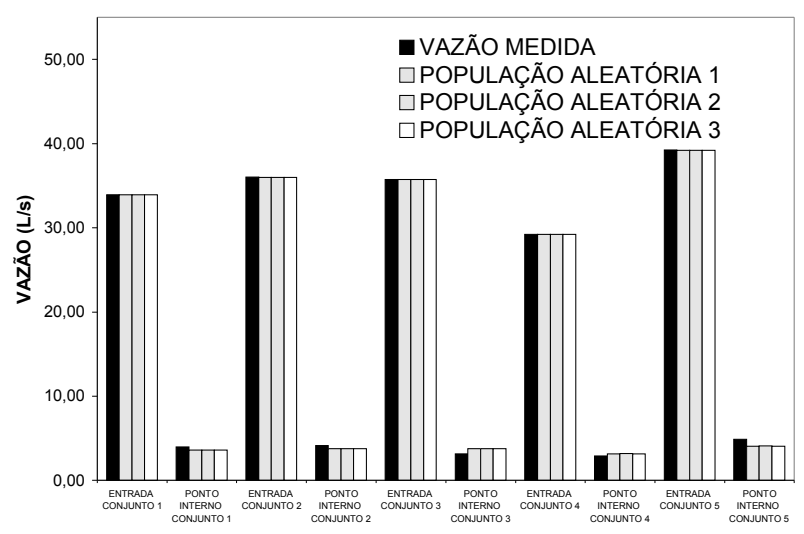

Figura 34 - Vazões medidas e simuladas para todas as populações aleatórias (rotina Silva (2003)) 


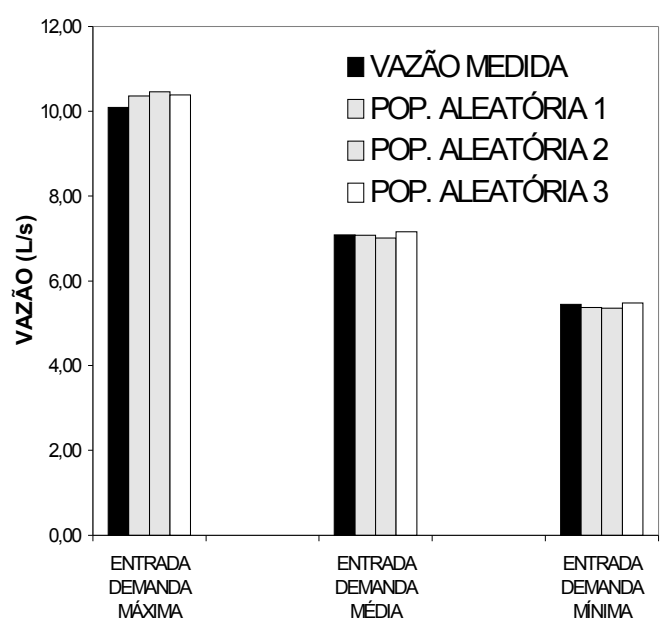

Figura 35 - Vazões medidas e simuladas para todas as populações aleatórias (rotina Caliman et. al. 2002)

$\mathrm{Na}$ Figura 34, são mostados os últimos valores obtidos da rotina de Silva (2003), a cada iteração, para todas as populações aleatórias iniciais. É observado que para todas as populações aleatórias, os valores se encontram muito próximos dos valores observados.

A análise foi feita também para Caliman et al. (2001), portanto se fez uso de apenas o ponto da entrada do setor para análise de vazões. Observa-se proximidade dos valores para todas as populações aleatórias analisadas.

\section{CONCLUSÕES}

O presente trabalho apresenta um modelo iterativo de duas fases para a calibração de modelos de redes de distribuição de água para abastecimento, contemplando vazamentos. As variáveis de decisão da primeira fase são basicamente as rugosidades nos trechos da rede e localização de acessórios responsáveis por perdas de carga localizadas. No segundo módulo determinam-se os parâmetros da curva pressão vazamento $(\mathrm{C} 1$ e N1). As variáveis de estado utilizadas para ambos os módulos foram às vazões e pressões na rede, cujos valores simulados foram comparados com os valores medidos. Para os dois módulos, a ferramenta de busca utilizada foi os algoritmos genéticos.

A aplicação foi feita para um setor da Cidade de São Carlos, S.P., Brasil; de tamanho representativo, que foi tratado sem simplificações e cujos levantamentos de campo foram realizados por autores deste artigo.

Analisou-se inicialmente o desenvolvimento da função de aptidão para ambos os módulos computacionais ao longo das iterações realizadas. Constatou-se que em um dos módulos a função de aptidão tende a aumentar o seu valor, enquanto que no segundo módulo, percebe-se uma diminuição de valores. Os dois módulos representam funções de aptidão de maximização, sendo que quando utilizadas separadamente, os valores tendem a aumentar a cada iteração de AG.

Constatou-se que os valores de C1 e N1 obtidos para populações aleatórias distintas são bastante próximos, demonstrando a consistência dos resultados obtidos.

Os valores de rugosidades dos trechos atribuídos a presença de acessórios variam pouco, ao longo das iterações dos dois módulos, conforme mostrado nas Figuras 14, 16 e 18.

Para as rugosidades atribuídas aos setores, nota-se oscilação maior no setor 2 (amianto) que no setor 1 (pvc), provavelmente pela maior fragilidade do material.

Tratando-se de uma rede real de tamanho representativo e sem simplificações, as simulações requerem um tempo computacional muito elevado, (chegando a dias de processamento por iteração de cada módulo), as simulações foram realizadas apenas para 3 populações aleatórias distintas. Dos 23 acessórios (trechos com rugosidades maiores que as atribuídas aos setores da rede) previstos no modelo, 18 foram localizados com frequência acima de $75 \%$.

Tanto para o módulo 1 (Silva (2003)), quanto para o módulo 2 (Caliman et al. (2001)), os valores de pressões simulados chegam, para a maioria dos nós de monitoramento muito próximos dos valores medidos, atendendo aos critérios internacionais. Percebeu-se que os valores oscilaram pouco, ao longo das iterações de cada módulo, e para as populações aleatórias.

A mesma aproximação ocorrida entre os valores simulados e medidos de pressão ocorreu para os valores da vazão.

Finalmente, conclui-se que a sistemática de busca usada e este procedimento de dois passos proposto mostraram-se apropriados para calibração de modelos de redes de distribuição de água, com vazamentos expressivos. Atualmente estudos vêm sendo desenvolvidos considerando o consumo variável com a pressão como um aprimoramento do modelo.

\section{AGRADEDIMENTOS}

Os autores agradecem à FINEP como agência financiadora do projeto RECOPE- REHIDRO, em que se insere o presente estudo; ao SAAE - São Carlos e sua equipe pelo apoio logístico no desenvolvimento deste trabalho e à FAPESP pela concessão de bolsa ao primeiro e terceiro autores do trabalho. 


\section{REFERÊNCIAS}

BOULOS, P.F.; WOOD, D.J. (1990). Explicit Calculation of Pipe- Network Parameters. J. Hydr. Engrg.,ASCE, v.116, n.11, p.1329-1344.

CALIMAN, R. O., SILVA, F. G. B., REIS, L. F. R., PORTO, R. M., CHAUDRHY, F. H. (2001) Determinação de parâmetros do modelo pressão-vazamento para um subsetor da cidade de São Carlos-SP com utilização de Algoritmos Genéticos. Anais do XIV Simpósio Brasileiro de Recursos Hídricos e V Simpósio de Hidráulica e Recursos Hídricos dos Países de Língua Oficial Portuguesa, Aracajú.

GERMANOPOULOS, G; JOWITT, P.W. (1989). Leakage reduction by excess pressure minimization in a water supply network. Proc. Instn Civ. Engrs Part 2, June, p. 195-214.

GOLDBERG, D.E. (1989).Genetic Algorithms in Search, Optimization, and Machine Learning. Addison-Wesley, Reading, Massachusetts, USA.

JOWITT, P.W.; XU, C. (1990). Optimal Valve Control in Water Distribution Networks. Journal of Water Resources Planning and Management, v.116, n.4, p.455-472, July.

LIGGETT, J.A.; CHEN, L.C. (1994). Inverse transient analysis in pipe networks. J.Hydr. Engrg, ASCE, v.120, n.8, p.934955.

MCKINNEY, D.C.LIN, M.D.(1994). Genetic algorithm solution of groundwater management models. J. Water Resourc, vol. 30, n.6, p-1897-1906.

ORMSBEE, L.E.; WOOD, D.J. (1986). Hydraulic Design Algorithm for Pipe Networks. J. Hydr. Engrg., ASCE, v.112, n.12, p.1195-1207.

ORMSBEE, L.E. (1989). Implicit Network Calibration. J.Water Res. Plng and Mgmt, ASCE, v.115, n.2, p.243-257.

PEZZINGA,G.;GUELI ,R. (1998). Optimal Location of Control Valves in Water Supply Networks by Genetic Algorithm. Discussion. Journal of Water Resources Planning and Management, v. 125, n. 1,p. 67.

PORTO, R.M. (1998). Hidráulica Básica - Projeto Reenge - EESCUSP.

PUDAR, R.S.; LIGGETT, J.A. (1992). Leaks in Pipe Network . J. Hydr. Engrg., ASCE, v.118. n.7, .1031-1046.

REIS, L.F.R.; PORTO, R.M.; CHAUDHRY, F.H. (1997). Optimal Location of Valves in Pipe Networks By Genetic Algorithm. Journal of Water Resources Planning and Management, v.123, n.6, p.317-326.

RITZEL, B.J.; EHEART, W. (1994). Using genetic algorithms to solve a multiple objetive groundwater pollution containment problem. J.Water Resouc. v.30, n.5, p.1589 1603.

SAVIC, D.A.; WALTERS, G.A. (1997). Evolving Sustainable Water Networks. Hydrological Sciences. Journal des Sciences Hydrologiques, v.42. n.4, p.545-564.
SANTOS, A. (2000). Estudo das perdas por vazamento aplicado a um setor da rede de abastecimento de São Carlos, SP. 114p. Dissertação (Mestrado) - Escola de Engenharia de São Carlos, Universidade de São Paulo.

SHAMIR, U. \& HOWARD, C.D.D. (1977). Engineering Analysis of Water Distribution Systens. Journal of the American Water Works Association, v.69, n.9, p.510-514.

SILVA, F.G.B. (2003). Estudos de calibração de redes de distribuição de água através de algoritmos genéticos (AGs). Tese (Doutorado) $r$ apresentada a - Escola de Engenharia de São Carlos, Universidade de São Paulo.

SILVA, F.G.B; REIS, L.F.R. (2002) Comparative analysis of diferent schemes for implementing genetic algorithms (GAs) in calibration of water supply distribution systems. Artigo submetido ao Journal of the Brazilian Computer Society.

SIMPSON, A.R.; DANDY, G.C. ; MURPHY, LAURENCE (1994). Genetic Algorithms Compared to Other Techniques for Pipe Optimization. Jounal of Water Resources Planning and Mannagement, v.120, n.4, p.423443.

TUCCIARELLI, T.; CRIMINISI, A.; TERMINI, D. (1999). Leak Analysis in Pipeline Systems by Means of Optimal Valve Regulation, ASCE, v.125, n.3, p.277-285.

VAIRAVAMOORTHY, K.; LUMBERS, J.(1998);. Leakage Reduction in Water Distribution Systems: Optimal Valve Control. Journal of Hidraulic Engineering, v.124, n.11, p.1146-1153, Nov.

WALSKI, T.M. (1983).Technique for Calibrating Network Models. J. Water Res. Plng and Mgmt, ASCE, v. 109, n.4, p.360-372.

WALTERS, G.A.; SAVIC, D.A.; MORLEY, M.;WERNER, D.S.(1998). Calibration of Water Distribution Network Models Using Genetic Algorithms. University of Exeter. School of Engineering.HYDROSOFT 1998 ( Inglaterra).

\section{Water supply network calibration analysis ap- plied to a real network sector - an approach tak- ing leakage into account}

\section{ABSTRACT}

Physical changes occurring over time require that hydraulic models to forecast the behavior of water distribution networks have their parameters reevaluated through calibration. There are several difficulties inherent to the calibration process of real networks, amongst which one can highlight those resulting from poor existing records such as uncertainty about the existence and position of networks valves. Many calibration methods have been proposed in literature, usually based on several analytical equations and optimization techniques. The need to estimate network parameters in terms of roughness and local parameters of pressure and leakage relations for systems subject to relevant leakage can be recognized. An iterative 
Calibração de um Modelo de rede de Distribuição de Água para um Setor de Abastecimento Real Contemplando Vazamentos

two-step calibration method is proposed here, in which the GAs (genetic algorithms) are used as a tool to resolve corresponding inverse problems, whose results prove robust to identify roughness, sections with valves and leakage model parameters.

Key Words: water supply distribution systems, genetics algorithms, calibration. 